\title{
Design of DC-DC Converter Bench Controlled by an Arduino Microcontroller
}

\author{
Moez Youssef ${ }^{1}$ \\ ${ }^{1}$ Associate Professor, \\ Department of Electromechanical Engineering, \\ Military Academy, Foundouk Jedid, Nabeul, Tunisia. \\ Chokri Boubahri ${ }^{3}$ \\ ${ }^{3}$ Assistant Professor, \\ Department of Electromechanical Engineering, \\ Military Academy, Foundouk Jedid, Nabeul, Tunisia.
}

\author{
Fethi Aloui ${ }^{2}$ \\ ${ }^{2}$ Assistant Professor,
}

Department of Electromechanical Engineering, Military Academy, Foundouk Jedid, Nabeul, Tunisia.

\section{Seifallah Fetni 4 \\ ${ }^{4}$ Assistant,}

Department of Electromechanical Engineering, Military Academy, Foundouk Jedid, Nabeul, Tunisia.

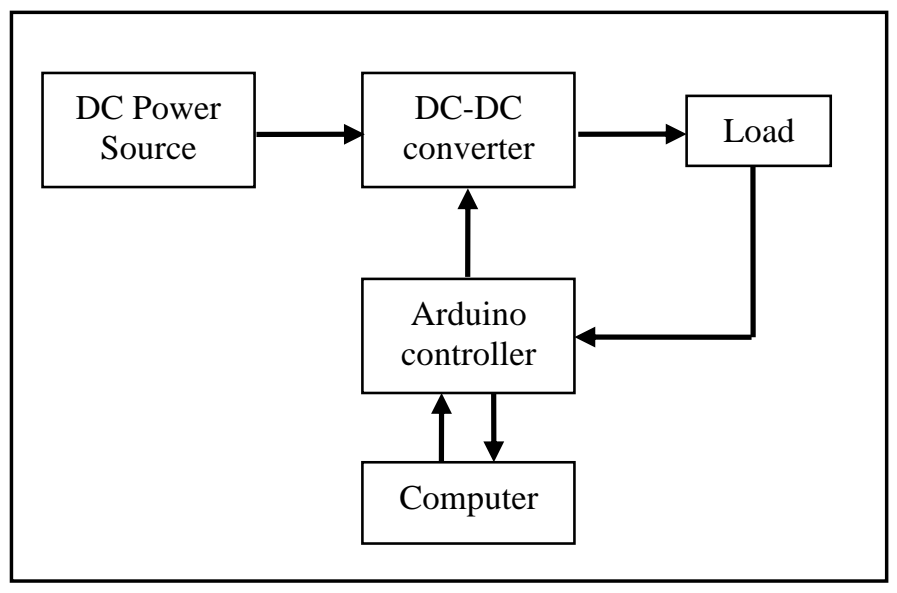

Fig.1: Block diagram

\section{CONTROL CIRCUIT}

The control circuit is shown in Fig.2.

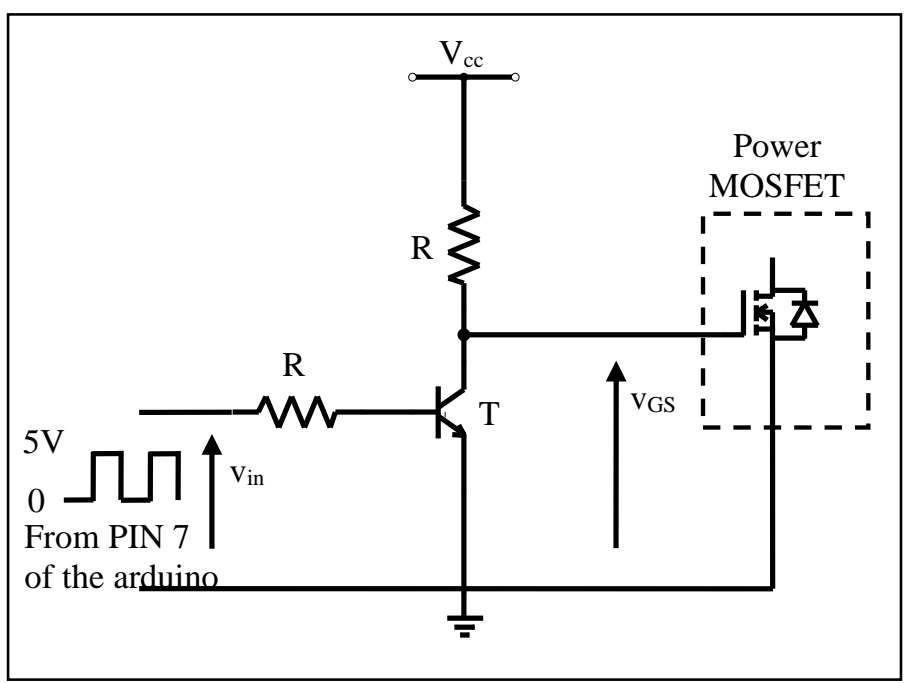

Fig.2: Control circuit 
The type and the values of the components used are as follows:

TABLE I. components of the control circuit

\begin{tabular}{|c|c|}
\hline T: NPN transistor & $2 \mathrm{~N} 2222$ \\
\hline R: resistor & $1 \mathrm{k} \Omega$ \\
\hline $\mathrm{V}_{\mathrm{cc}}$ : DC source & $15 \mathrm{~V}$ \\
\hline
\end{tabular}

$\mathrm{V}_{\text {in }}$ is the voltage delivered by the PIN7 of the Arduino. $\mathrm{V}_{\text {in }}$ is a square-wave voltage, the low level is $0 \mathrm{~V}$ and the high level is $5 \mathrm{~V}$. In order to have a square-wave voltage with a frequency $\mathrm{f}=1 \mathrm{kHz}$ and a duty cycle $\mathrm{D}=0.6$, the following code must be written with the Arduino Software (IDE).

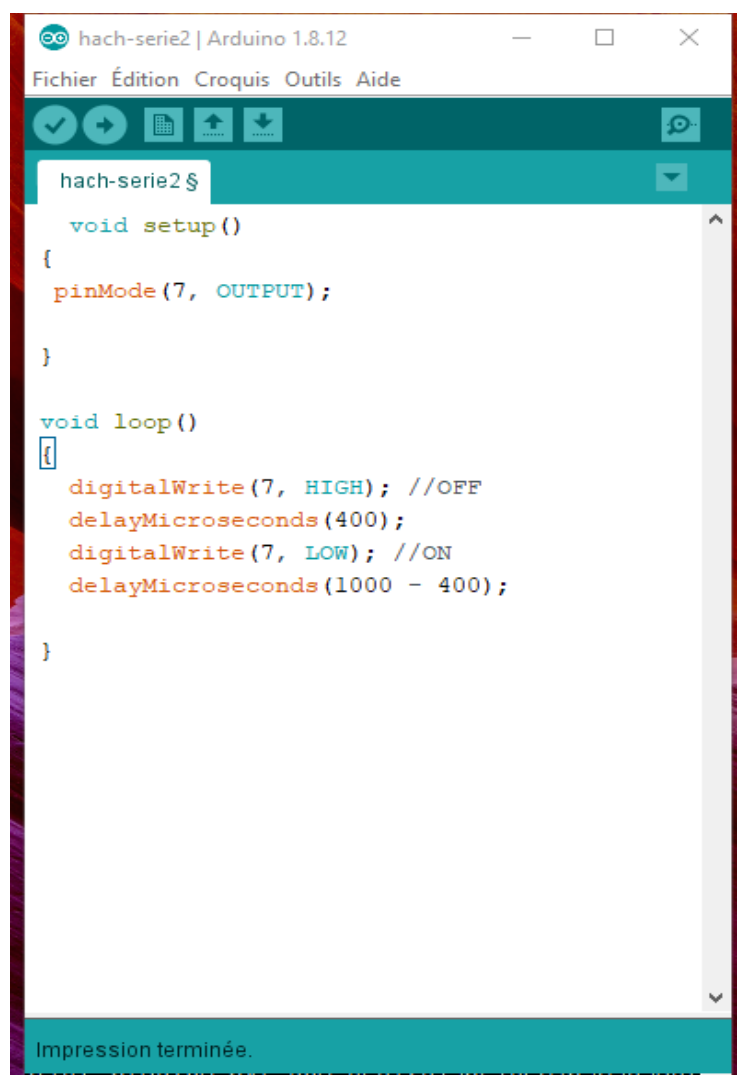

Fig.3: Arduino code

When $\mathrm{V}_{\text {in }}$ is at the low level $(0 \mathrm{~V})$, the transistor $\mathrm{T}$ is $\mathrm{OFF}$ (open), then $\mathrm{v}_{\mathrm{GS}} \approx \mathrm{V}_{\mathrm{cc}}=15 \mathrm{~V}$ (for $\mathrm{R}=1 \mathrm{k} \Omega$, the voltage across the resistor $\mathrm{R}$ can be neglected).

When $\mathrm{V}_{\text {in }}$ is at the high level $(5 \mathrm{~V})$, the transistor $\mathrm{T}$ is $\mathrm{ON}$ (saturated), then $\mathrm{v}_{\mathrm{GS}} \approx 0 \mathrm{~V}$.

Fig.4 shows a simulation of the control circuit on Proteus.

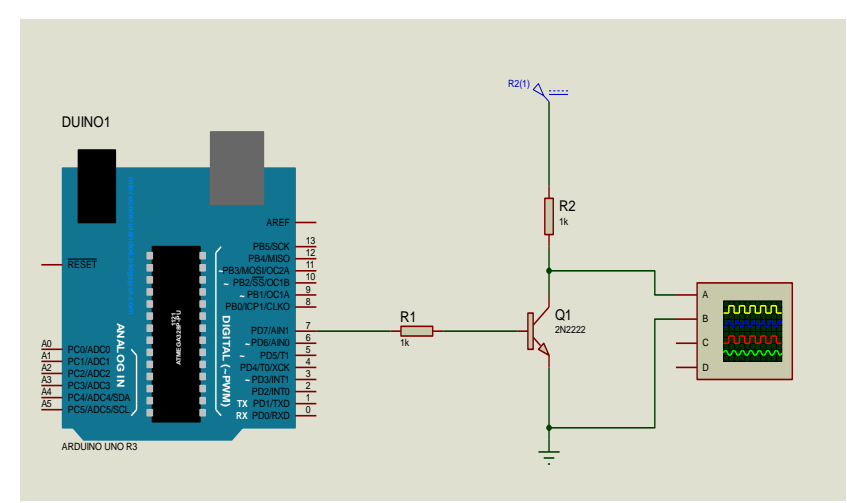

Fig.4: Proteus simulation of the control circuit

The result of the control circuit simulation is as follows.

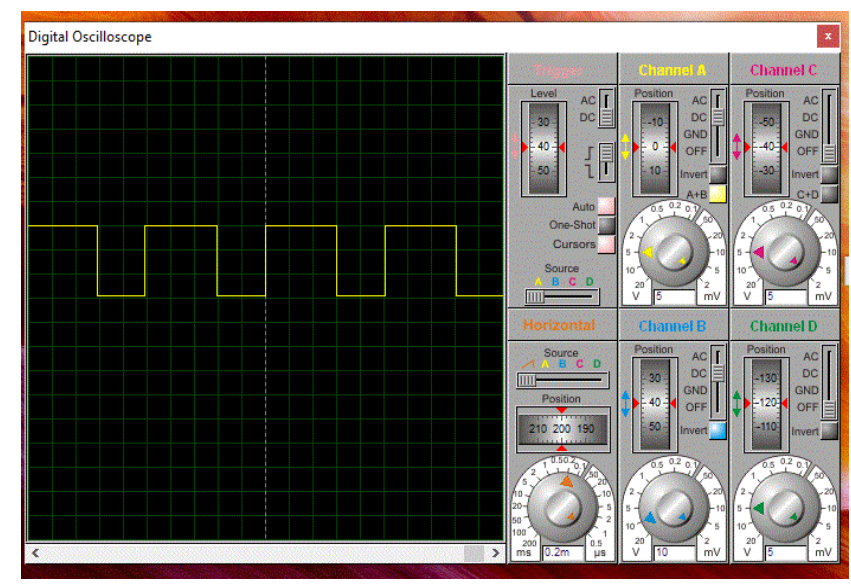

Fig.5: control voltage simulation

After simulation, the complete control circuit has been tested, the following result is obtained:

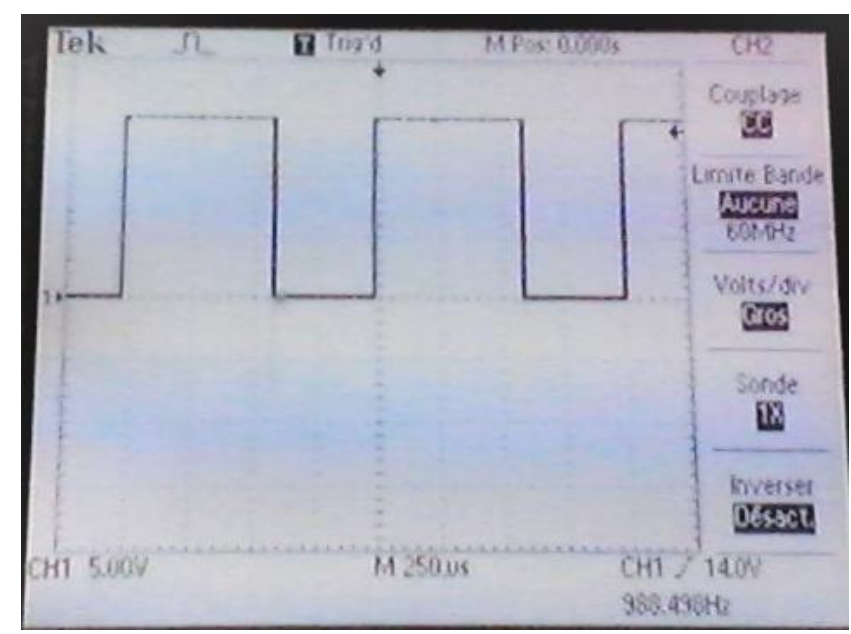

Fig.6: control voltage measured

\section{POWER CIRCUIT}

Experiments are carried out for three DC-DC converters structures that are: Buck converter, Boost converter and BuckBoost converter.

The type and the values of the components used are as follows: 
TABLE II. Components of the power circuit

\begin{tabular}{|c|c|}
\hline M: MOSFET & IRF540 \\
\hline D: Diode & BYY56 \\
\hline R: Resistor & $25 \Omega$ \\
\hline L: Inductor & $0.1 \mathrm{H}$ \\
\hline C: Capacitor & $54 \mu \mathrm{F}$ \\
\hline $\mathrm{V}_{\text {s }}$ : DC source & $15 \mathrm{~V}$ \\
\hline
\end{tabular}

\section{A. Buck converter}

The buck converter is shown in Fig.7. It operates by periodically opening and closing an electronic switch (MOSFET). It is called a buck converter because the output voltage is less than the input.

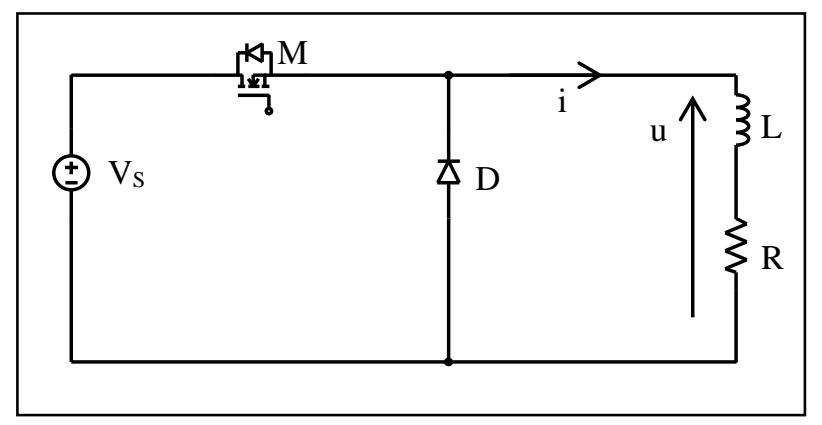

Fig.7: Buck converter

In practice, the following configuration (Fig.8) is preferred. Its main advantage is the common ground for both control and power circuits.

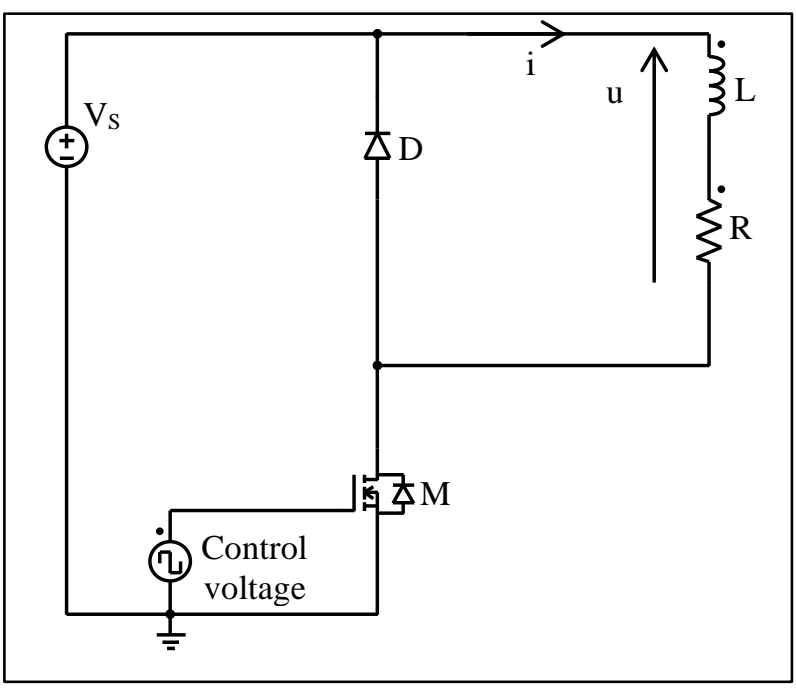

Fig.8: Buck converter with common ground

Theoretical waveforms for buck converter are as follows:

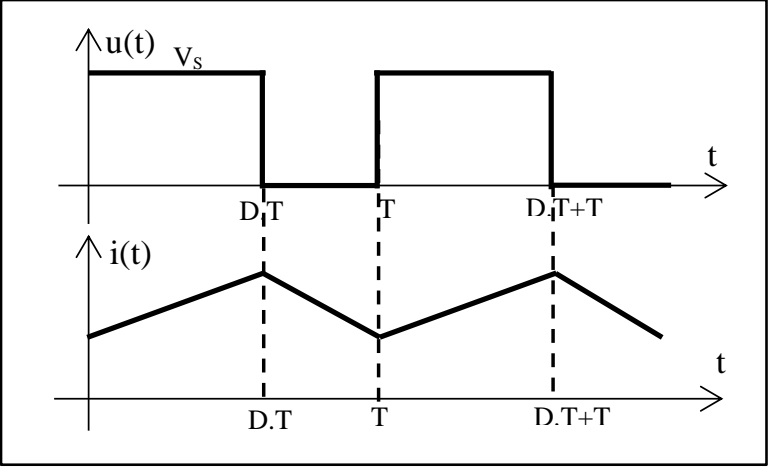

Fig.9: Theoretical waveforms of the buck converter

$\mathrm{u}(\mathrm{t})$ and $\mathrm{i}(\mathrm{t})$ are output (load) voltage and current.

The average of the output voltage $\mathrm{u}(\mathrm{t})$ is given by:

$$
\bar{U}=D \cdot V_{S}
$$

$\mathrm{D}$ is the duty cycle.

\section{B. Boost converter}

The boost converter is shown in Fig.10. It is called a boost converter because the output voltage is larger than the input.

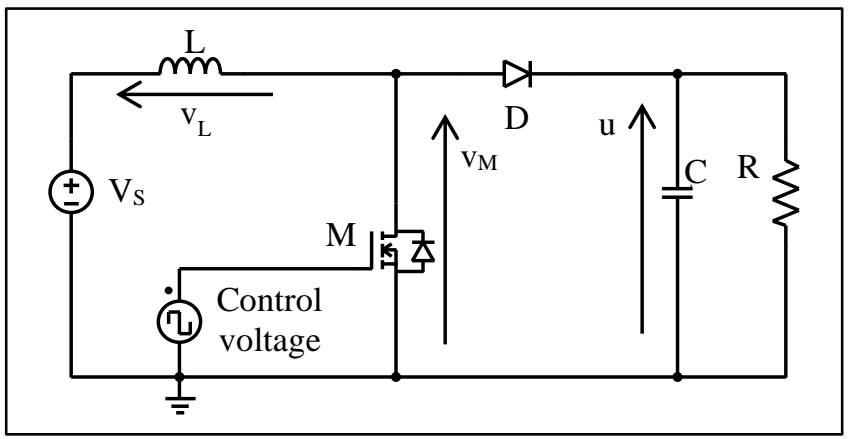

Fig.10: Boost converter

In theory, the capacitor $\mathrm{C}$ is considered so large that the output voltage $\mathrm{u}$ is held constant at $u=U$.

The analysis proceeds by examining the inductor voltage $\left(v_{L}\right)$ and the switch voltage $\left(v_{M}\right)$ for the switch closed and again for the switch open.

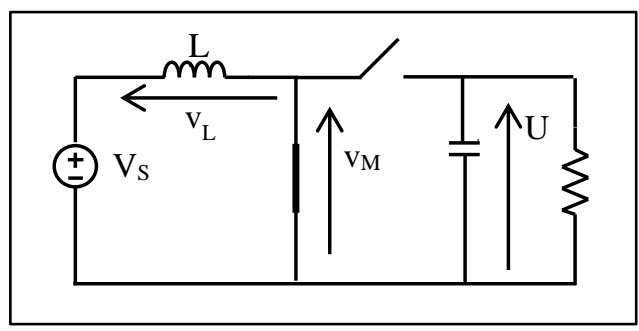

Fig.11: Equivalent circuit for the switch closed

When the switch is closed:

$$
\left\{\begin{array}{l}
v_{L}=V_{S} \\
v_{M}=0
\end{array}\right.
$$




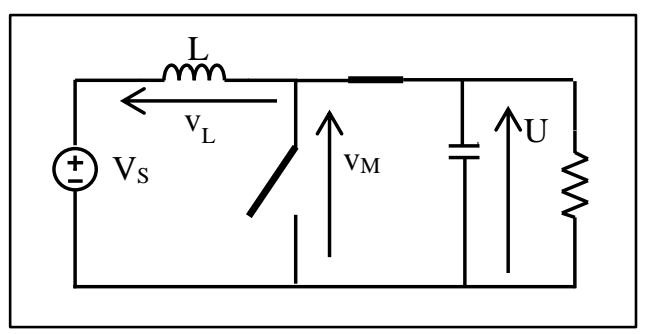

Fig.12: Equivalent circuit for the switch open

When the switch is open:

$$
\left\{\begin{array}{c}
v_{L}=V_{S}-U \\
v_{M}=U
\end{array}\right.
$$

Theoretical waveforms for boost converter are as follows:

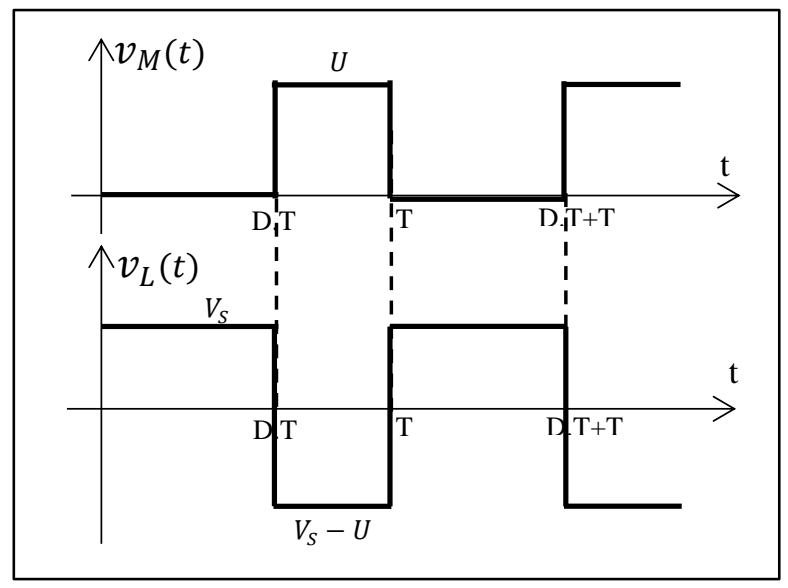

Fig.13: Theoretical waveforms of the boost converter

The average inductor voltage must be zero for periodic operation, then:

$$
D \cdot V_{S}+(1-D)\left(V_{S}-U\right)=0
$$

Which gives:

$$
U=\frac{V_{S}}{1-D}
$$

Since $0 \leq D \leq 1$, then $U \geq V_{S}$

\section{Buck-boost converter}

The buck-boost converter is shown in Fig.14. The output voltage of the buck-boost converter can be either higher or lower than the input voltage.

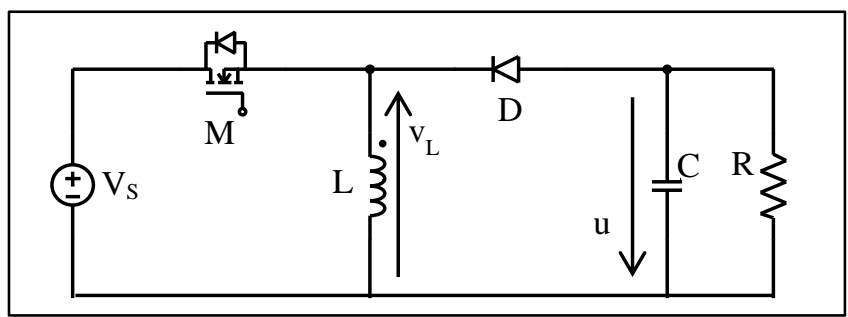

Fig.14: Buck-boost converter

In practice, the following configuration (Fig.15) is preferred. Its main advantage is the common ground for both control and power circuits.

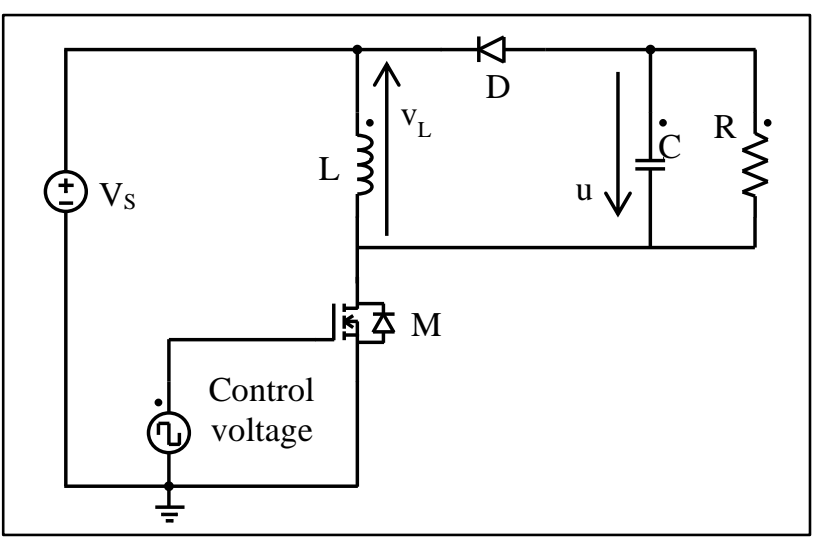

Fig.15: Buck-boost converter with common ground

In theory, the capacitor $\mathrm{C}$ is considered so large that the output voltage $u$ is held constant at $u=U$.

The analysis proceeds by examining the inductor voltage $\left(v_{L}\right)$ for the switch closed and again for the switch open.

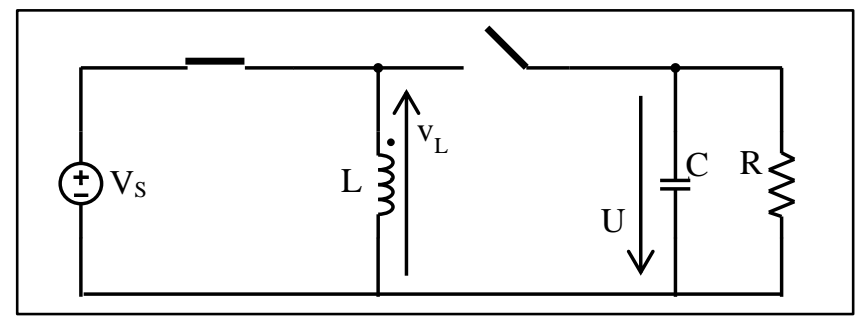

Fig.16: Equivalent circuit for the switch closed

When the switch is closed:

$v_{L}=V_{S}$

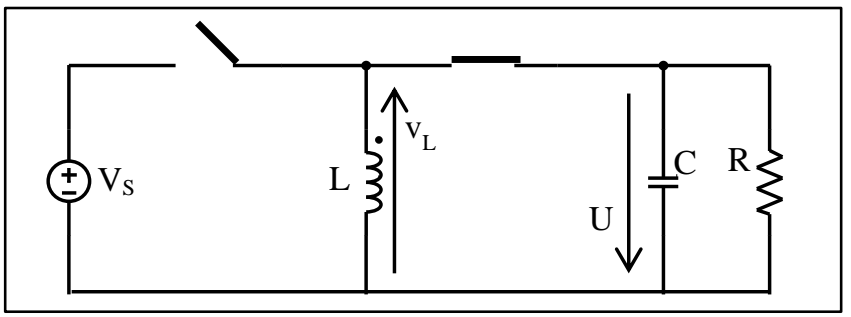

Fig.17: Equivalent circuit for the switch open

When the switch is open:

$$
v_{L}=-U
$$

Theoretical inductor voltage $v_{L}$ for buck-boost converter is as follows:

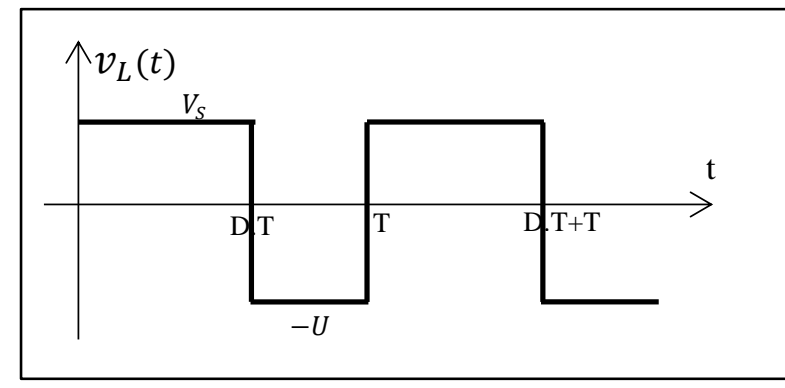

Fig.18: Theoretical inductor voltage $v_{L}$ for buck-boost converter 
The average inductor voltage must be zero for periodic operation, then:

$$
\text { D. } V_{S}+(1-D) \times(-U)=0
$$

Which gives:

$$
U=\frac{D \cdot V_{S}}{1-D}
$$

If $0.5<D, U>V_{S}:$ the output voltage is larger than the input.

If $D<0.5, U<V_{S}$ : the output voltage is smaller than the input.

\section{SimUlations AND RESULTS}

In this section, Proteus simulations and real measurements are shown for the three configurations of DC-DC converters.

\section{A. Buck converter}

The complete buck converter circuit (control + power) is simulated using the Proteus software. Simulation is carried out for the practical values.

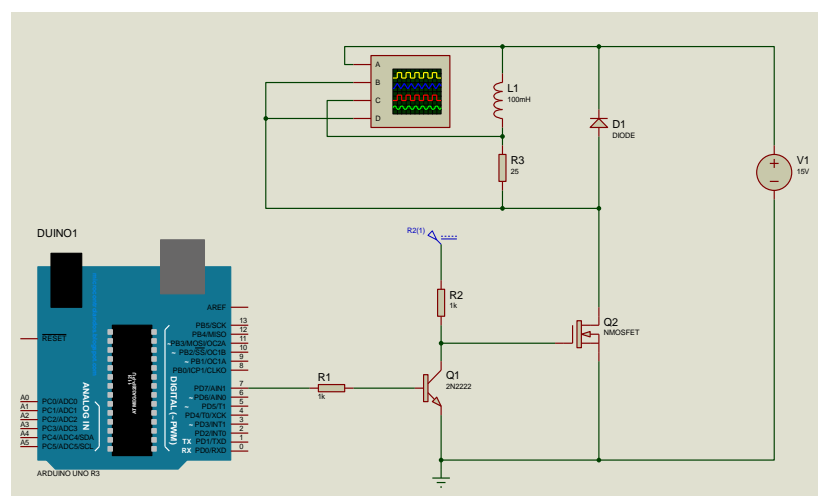

Fig.19: Proteus simulation of the buck converter

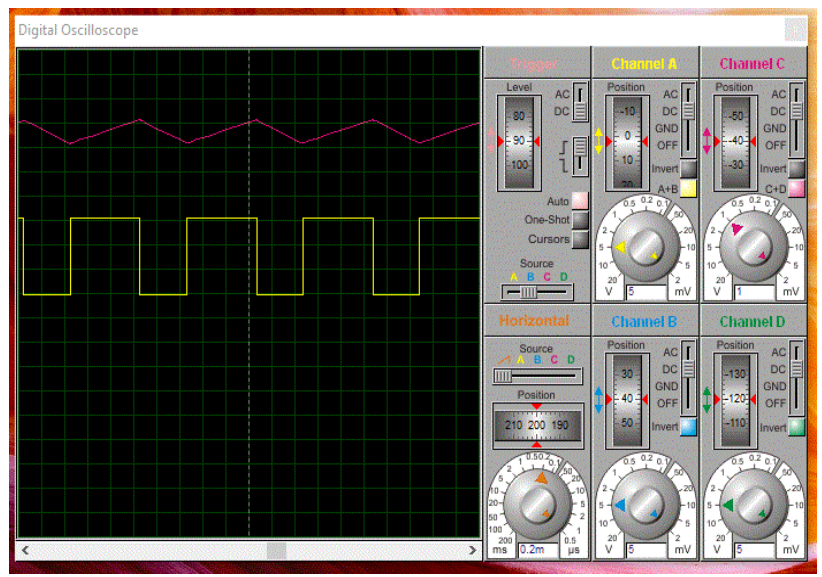

Fig.20: Proteus waveforms

The yellow waveform represents the load current and the red waveform represents the load voltage.

Practical Measurements are in accordance with theory and simulation as shown in Fig. 21.

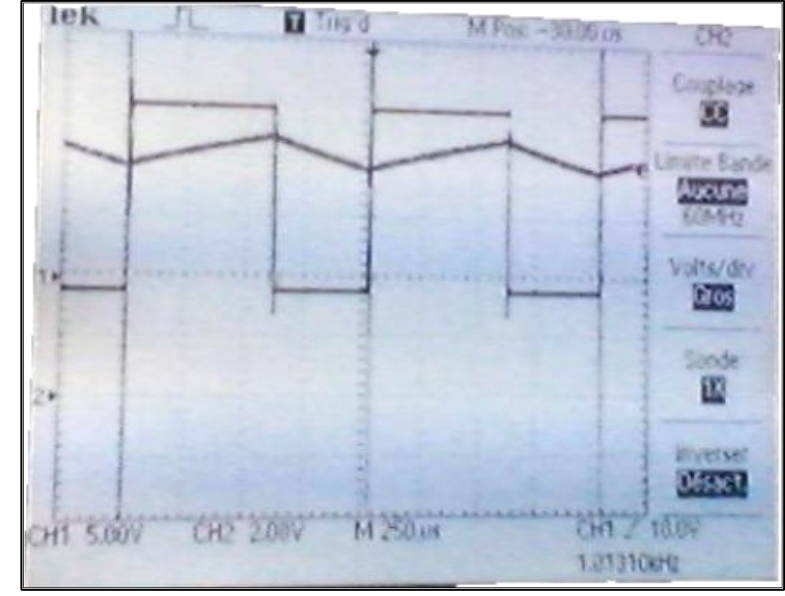

Fig.21: Measured load current and voltage for buck converter

\section{B. Boost converter}

The complete boost converter circuit (control + power) is simulated using the Proteus software. Simulation is carried out for the practical values.

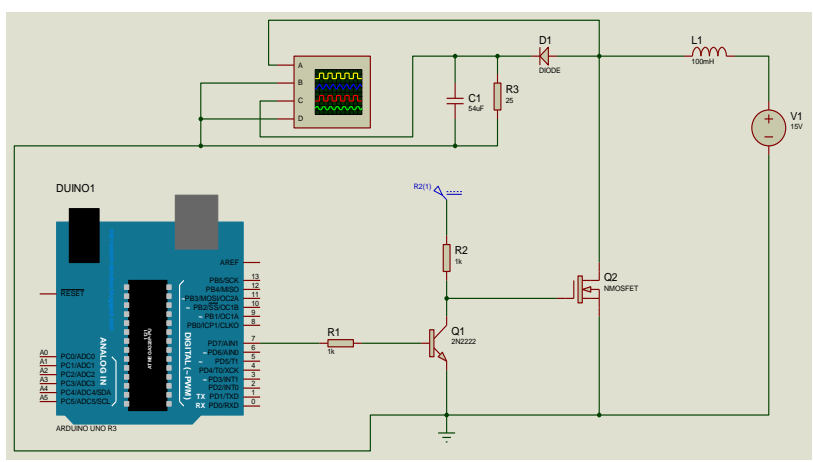

Fig.22: Proteus simulation of the boost converter

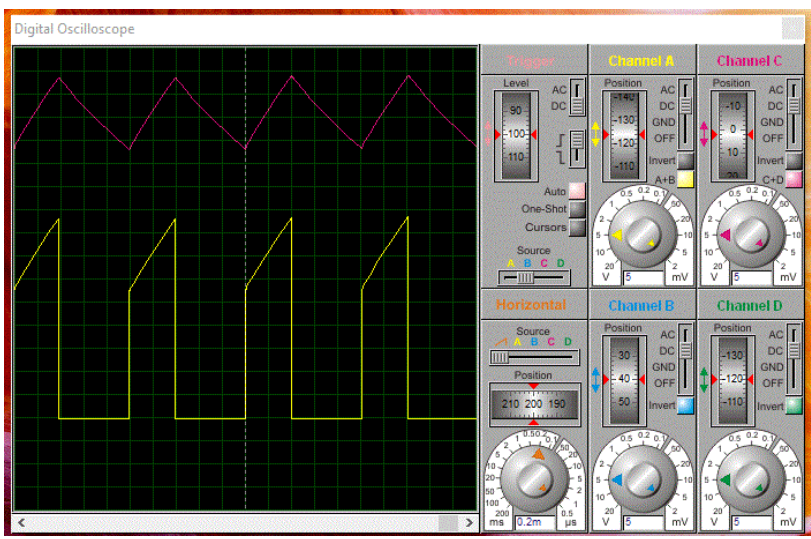

Fig.23: Proteus waveforms of the boost converter

The yellow waveform represents the switch voltage $v_{M}$ and the red waveform represents the load voltage $u$. Since the capacitor $\mathrm{C}$ has a finite value $(\mathrm{C}=54 \mu \mathrm{F})$, the output voltage $\mathrm{u}$ is not constant (it has a ripple). Practical measurements confirm Proteus simulation as shown in Fig.24. 


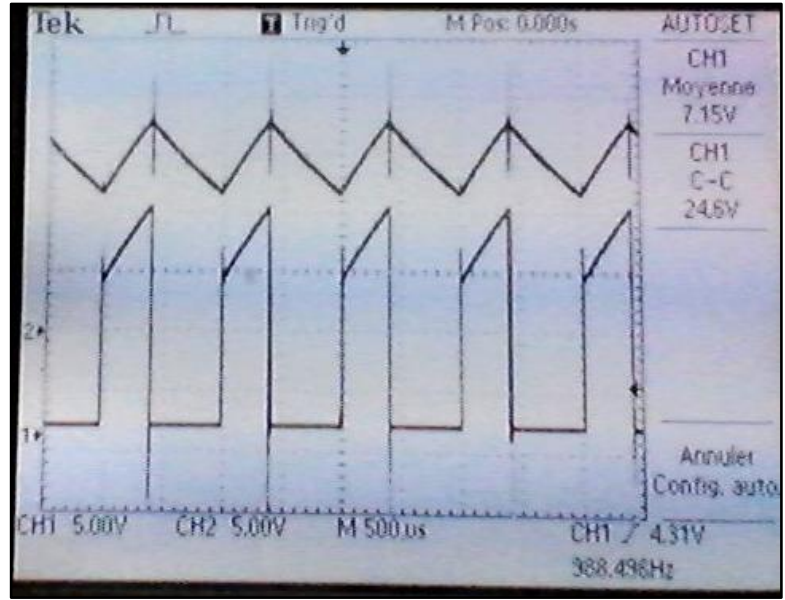

Fig.24: Measured load and switch voltages for boost converter

\section{Buck boost converter}

The complete buck-boost converter circuit (control + power) is simulated using the Proteus software. Simulation is carried out for the practical values

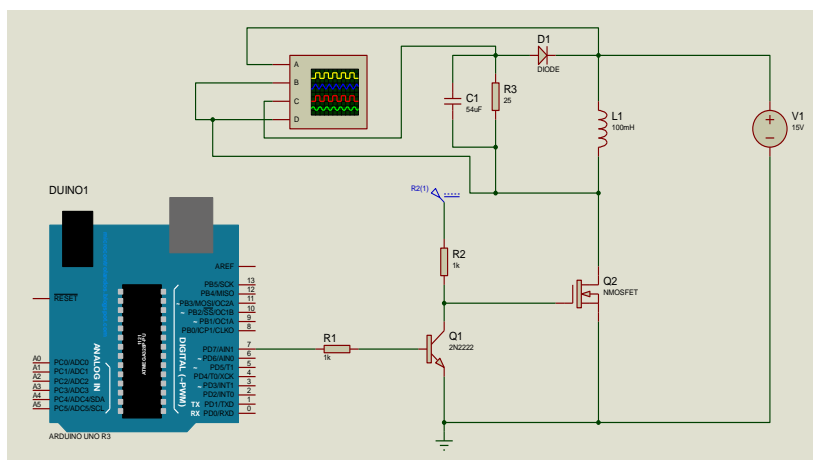

Fig.25: Proteus simulation of the buck-boost converter

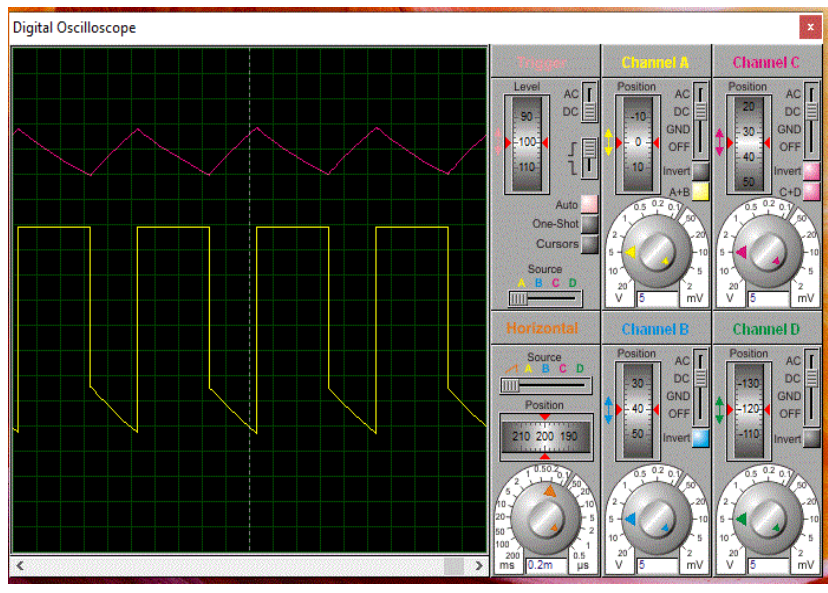

Fig.26: Proteus waveforms of the buck-boost converter

The yellow waveform represents the inductor voltage $v_{L}$ and the red waveform represents the load voltage $u$. Since the capacitor $\mathrm{C}$ has a finite value $(\mathrm{C}=54 \mu \mathrm{F})$, the output voltage $\mathrm{u}$ is not constant (it has a ripple). Practical measurements confirm Proteus simulation as shown in Fig.27.

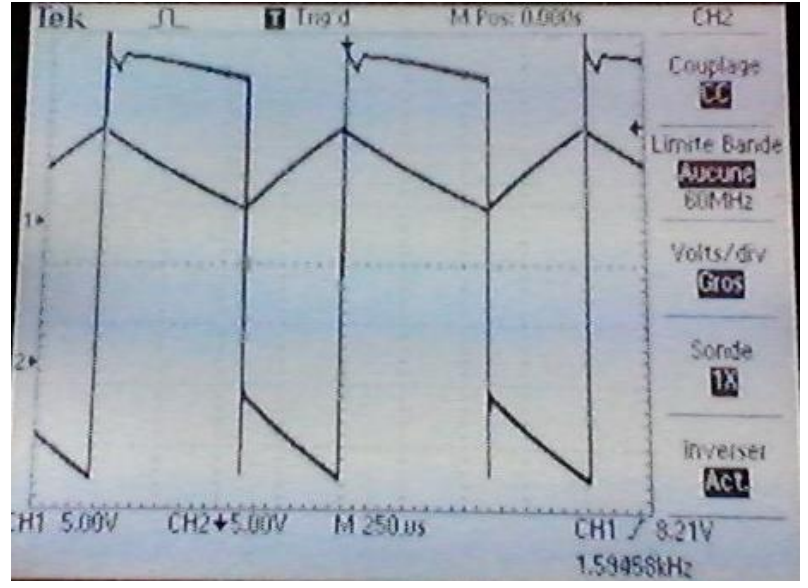

Fig.27: Measured load and inductor voltages for buck-boost converter

\section{CONCLUSION}

In this project, a DC-DC converter bench is designed. This experimental bench is a multi-topology bench. It allows students to study the elementary DC-DC converters that are buck, boost and buck-boost converters. For this DC-DC converter, the pulse needed for switching semiconductor device is generated using the Arduino Uno.

Before performing experimental measurements, simulations with the Proteus software are carried out. The simulations results obtained are in accordance with measurements.

This project highlights that Arduino offers a simple and efficient way to control power converters.

\section{REFERENCES}

[1] R. Saravanamoorthi, P. Rathinavel, E. Sandhya and K.M. Manu, "Arduino Based Pwm Output Voltage Control of a DC-DC Boost Converter," International Journal of Engineering Research \& Technology (IJERT), Vol. 6 Issue 03, March-2017, pp. 348-350.

[2] C. Buccella, C. Cecati and H. Latafat, "Digital Control of Power Converters-A Survey," IEEE Transactions on Industrial Informatics, VOL. 8, NO. 3, August 2012, pp. 437-447.

[3] S.A. Lopa, S. Hossain, M. K. Hasan and T. K. Chakraborty, "Design and Simulation of DC-DC Converters," International Research Journal of Engineering and Technology (IRJET), Vol. 03 Issue 01, Jan-2016, pp. 63-70.

[4] T. Bouguettaya and N. Obeidi, "Commande d'un Moteur à Courant Continu Alimenté par un Hacheur avec la Carte Arduino," Department of electrical engineering, El-Oued University, Algeria. Submitted for the requirements for the Degree of Master in Electric Control, May2016.

[5] [Online]. Available: https://www.f-legrand.fr/scidoc/index.html.

[6] M. H. Rashid and F. L. Luo, "Power Electronics Handbook: Devices, Circuits and Applications, " 2nd ed. New York: Elsevier Academic, 2006 